\title{
Minicuentos: inversión de propósitos en protagonistas, estructura, función y efecto ${ }^{1}$
}

\author{
María Antonieta Gómez Goyeneche \\ Doctorado en Teoría de la Literatura y del Arte y Literatura Comparada \\ Universidad del Valle \\ https://orcid.org/0000-0003-2305-5066 \\ maria.a.gomez@.correounivalle.edu.co
}

\begin{abstract}
Resumen
El presente estudio se propone discernir, a nivel teórico, pautas estructurales, función y efecto de la inversión de propósitos de protagonistas en minicuentos, con base en un ejercicio de literatura comparada sobre aspectos comunes y matizaciones diferenciales ejemplificadas en obras colombianas.
\end{abstract}

Palabras clave: inversión; literatura colombiana; minicuentos; propósito; protagonistas.

\section{Short-short stories: investment of purposes in protagonists, structure, function and effect}

\begin{abstract}
Hbstract
The present study intends to discern at a theoretical level, structural guidelines, function and effect of the investment of protagonists' intentions in short-short stories, based on an exercise of comparative literature on common aspects and differential nuances exemplified in Colombian works.
\end{abstract}

Keywords: Colombian literature; investment; protagonists; purpose; short-short stories.

Recibido: 26 de septiembre del 2020. Hprobado: 02 de diciembre del 2020

Artículo de reflexión

https://doi.org/10.25100/poligramas.v0i52.10977 1 Procedencia del artículo: Este estudio constituye un informe final de investigación registrado en la Vicerrectoría
de Investigaciones de la Universidad del Valle (Cl. 4393).

Esta obra está bajo una Licencia Creative Commons Atribución-NoComercial Compartirlgual 4.0 Internacional.

Universidad del Valle, Cail, Colombia 


\section{¿Cómo citar este artículo en MLH? - How to quote this article in MLA?}

Gómez Goyeneche, María Antonieta. "Minicuentos: inversión de propósitos en protagonistas, estructura, función y efecto" Poligramas 52 (2021) : e.2110977. Web. Fecha de acceso (día, mes en mayúscula y abreviado, y año).

En la definición del Diccionario de la lengua española, apropiada a este contexto, invertir consiste en "cambiar, sustituyéndolos por sus contrarios, la posición, el orden o el sentido de las cosas" (6: 879). La inversión como estrategia en la imaginación literaria permite fabular una lógica contraria a las leyes que conocemos en sus diversas manifestaciones. Por ejemplo, dentro de su variedad tipológica, se presentan inversiones biológicas (Gargantúa, en la novela de François Rabelais, nace por la oreja izquierda de su madre); inversiones de costumbres (en la abadía de Théléme, en esta misma novela, se fabulan de manera crítica inversiones de costumbres de estos lugares del siglo XVI); inversión, doble y metamorfosis (en la famosa novela de Robert Louis Stevenson, el honorable doctor Jekyll, a través de una pócima, pasa por una inversión para ser el malévolo señor Hyde, con un físico distinto); inversiones por tamaño (Alicia en el país de las maravillas, de Lewis Carroll, pasa por el procedimiento de la miniaturización y la gigantización de manera alterna); inversiones jerárquicas (en La muerte y la muerte de Quincas Berro Dágua de Jorge Amado, el protagonista pasa de ser un representante de la clase media burguesa a ser el rey de los pordioseros); inversiones de caracteres y cualidades propias (en ciertas fábulas, ratones persiguiendo a gatos, peces pescando hombres, leones alimentándose de forraje... ); entre otras posibilidades inversoras de roles, leyes físicas, lingüísticas...

La inversión es quizá uno de los procedimientos más usados en la imaginación, y aparece como recurso retórico, motivo o tema en el llamado adynaton, presente desde la antigua literatura grecolatina en el género de la poesía (cf. Ruiz Sánchez y Valverde Sánchez; Villalba de la Güida). Pero también en la historia de la literatura la inversión es una característica esencial del surgimiento del género de la novela, a través de lo que el teórico y crítico literario Mijaíl Bajtín (1990) Ilamó la carnavalización de la literatura, o la influencia de la cultura popular por medio de la festividad, en donde las inversiones jerárquico sociales, la parodia, la ironía, el mundo al revés, la entronización y desentronización de personajes, situaciones y cosas, entre 
otros parámetros inversores afines, entran en vigencia y permean sobre todo a la novela, además de los otros géneros.

Respecto al género del cuento, Boris Eichenbaum, uno de los formalistas rusos interesados en cómo se construyen las obras literarias, observaba en 1925: "el cuento se construye sobre la base de una contradicción, de una falta de coincidencia, de un error, de un contraste, etc." (151). Es decir, el procedimiento de la inversión puede ser también estratégico en su construcción y técnica narrativa, al igual que en el minicuento.

Entre las múltiples posibilidades existentes, además de las ya referidas, se da la alternativa de invertir algún propósito que se fijan los protagonistas de ciertos minicuentos -en nuestro interés- por un resultado contrario al final de la narración, contribuyendo, entre otros recursos posibles, al efecto de sorpresa y perplejidad que se agudiza en este tipo de narración. Interesa aquí este procedimiento de la inversión en el entramado de ciertos minicuentos: bajo qué pautas narrativas se construye la inversión de propósitos de los protagonistas, cuáles son sus funciones y su efecto.

Para ello, tengamos en cuenta, en primer término, el hecho de que un relato tiene cinco partes que conforman una estructura quinaria compuesta por: situación inicial - nudo - peripecias - desenlace - situación final.

A veces observamos una situación equilibrada al principio de la trama (del tipo 'Los personajes vivían apaciblemente. De pronto sucedió...'). Para poner la trama en movimiento se introducen motivos dinámicos que destruyen el equilibrio de la situación inicial. El conjunto de los motivos que rompen la inmovilidad de la situación inicial y que desencadenan la acción se llama el nudo. Habitualmente el nudo determina toda la evolución de la trama y la intriga se reduce a las variaciones de los motivos principales que han sido introducidos por el nudo. Estas variaciones se llaman peripecias (el paso de una situación a otra) ... La tensión dramática va creciendo a medida que se acerca el vuelco de la situación ... La tensión alcanza su culminación antes del desenlace (Tomashevski 207).

Después del desenlace, continúa Tomashevski, viene la situación final.

Según las asociaciones del crítico Eduardo Serrano Orejuela, "dada la breve extensión de los minicuentos, es frecuente que, en el caso de que tengan la estructura quinaria de Relato, 
esta no sea presentada en su totalidad, correspondiéndole al lector inferir la parte omitida" (2122). Se tendrá en cuenta esta estructura al interior de las pautas observadas en la construcción narrativa para la inversión de propósitos en protagonistas y su efecto en minicuentos.

Como ilustración en función teórica y comparativa, se estudian siete minicuentos de escritores colombianos: David Sánchez Juliao (1945-2011), con el minicuento «Ojo por ojo», de su colección El arca de Noé, publicada en 1976; Harold Kremer (1955), con «Los confusos», "La cierva y la leona» y «Robo», de su colección El combate (2004); Felipe Orozco (s. f.), con "Celebración», minicuento comprendido en su obra Seré breve (2014); Gustavo Laverde Sánchez (1977), con "Cadena alimenticia», publicado en Cuentos cuadrados (2005); y "Visita de pésame» de Adalberto Agudelo Duque (1943), en la Tercera antología del cuento corto colombiano, compilada por Bustamante Zamudio y Kremer (25). Al final de este estudio se presenta un anexo con estos minicuentos.

\section{Pautas estructurales en la inversión de propósitos en protagonistas}

Como constante en la construcción de ciertos minicuentos, son observables las siguientes pautas narrativas en la inversión de propósitos de los protagonistas: propósito - medios imprevisto - inversión. Estas pautas se presentan en minicuentos que bien pueden seguir toda la estructura quinaria de un relato (p. ej., "Ojo por ojo», "Los confusos», "La cierva y la leona», "Robo», "Cadena alimenticia», "Celebración»), o solo parcialmente (p. ej., "Visita de pésame»), tal como se ejemplificará siguiendo estrictamente el orden de la narración de cada uno de los minicuentos seleccionados dentro del interés aquí establecido.

\section{Propósito}

Se disciernen dos centros de atención básicos acerca del propósito de un protagonista: cómo se plantea en una narración y qué tipos existen según su índole.

Con relación a cómo se plantea un propósito, se presentan dos alternativas principales, que corresponden a matices diferentes dentro de la selección de los minicuentos:

a) Que el protagonista (persona o animal) de una narración tenga un propósito a partir del cual pueden surgir vicisitudes o dificultades inherentes. 
b) En la alternativa inversa, que el protagonista tenga una dificultad, planteada de manera explícita o implícita en la narración, y, para ello, genere un propósito.

Frente al propósito protagónico, se presenta, en algunos casos, un contrapropósito, ante todo cuando alguno(s) de los personajes son víctimas, justamente, de la motivación y acciones que genera el propósito.

Así, al protagonista del minicuento "Los confusos» le asiste el siguiente propósito, desde la situación inicial que determina el programa narrativo: "El monarca de aquel país, para perpetuarse en el poder, se propuso crear una escuela de la confusión" (Kremer 14). En tanto que, en «Robo», el propósito del cual parte la narración se encuentra en la siguiente intención y acción: "El ladrón arrancó el bolso de la desprevenida transeúnte y cuando empezó a correr la mujer tiró de la correa" (Kremer 61). Y en «Ojo por ojo», comienza la narración con el hecho de que el protagonista está "obstinado en conseguir el Premio Nobel de microbiología" (Sánchez Juliao 111). Ante cada uno de estos propósitos, se va a generar un contrapropósito, que representa la resistencia, generalmente cuando se da la dinámica victimario-víctima del propósito.

En otra alternativa, es una dificultad, explícita o implícita, anotaba, la que determina algún propósito. Así, en los minicuentos "La cierva y la leona», "Cadena alimenticia» y "Visita de pésame», el propósito surge de la dificultad de sobrevivencia de las víctimas dentro de las tensiones entre depredadores y presas, y los protagonistas son, precisamente, las presas.

De este modo, en la situación inicial de «La cierva y la leona»:

Lo ideal sería que la leona antes de atacar y devorar al pequeño ciervo, hablara con la madre del animalito y le dijera los motivos del crimen. Quizá la cierva la invitaría entonces a un trago porque tendría mucho de que hablar sobre ese tema, pues ya ha perdido tres ciervitos en las garras de leones, leopardos y otros depredadores. Pensaría la cierva: "Al fin y al cabo las dos somos madres, y hablaríamos de sentimientos y esas cosas" (Kremer 18).

Dificultad dentro de la ley natural de la "Cadena alimenticia», como titula su minicuento, precisamente, Gustavo Laverde Sánchez: "Los gusanos decidieron contratar a las zorras como guardaespaldas; así, los pollos y las gallinas, por más osados que fueran, no se atreverían a tocarlos" (21). 
En «Visita de pésame» comienza la narración con un desenlace, omitiendo situación inicial - nudo - peripecias. Y parte de un contrapropósito, ya consumado, el de los pájaros en su difícil situación ante un propósito (el de Salvador), y bajo la tensión victimario-víctimas:

A Manuel Salvador lo mataron los pájaros. En venganza por las tórtolas caídas, los colibríes y los gorriones asesinados merced a su ojo implacable con la cauchera de ocho líneas. Tal vez lo mataron por piedad, para que no sufriera en vida todas las muertes de los pichones huérfanos y los huevos abandonados en los nidos (Agudelo Duque 25).

En «Celebración», ante una dificultad no explícita en la narración, el protagonista parte del propósito de suicidarse: "Calculando el vacío desde su balcón, el angustiado Saúl observó el trasiego de la calle mucho más abajo y sopesó la caída. Midió también el vacío de su existencia, más [sic] concluyó, que a pesar de todo el balance era positivo. 'Mi vida está ya amortizada', pensó" (Orozco 38).

Desde la perspectiva sobre cuál es la índole de los propósitos, que atañe también a cómo se proyectan y reciben en el entorno narrado, son observables dos posibilidades básicas:

a) Propósitos y contrapropósitos utópicos, esto es, tomando la definición general del término utopía: "plan, proyecto, doctrina o sistema optimista que aparece como irrealizable en el momento de su formulación" (Diccionario de la lengua española 10: 1534). Se trata, en nuestro contexto, de intenciones que surgen en el ideal de un protagonista, pero difíciles de lograr al retar al máximo las posibilidades individuales, o también, por ejemplo, al implicar la completa inversión del sistema de la naturaleza o de lo social. En algunos casos, responden a la situación donde el protagonista tiene una dificultad para la que genera un propósito o un contrapropósito mediante el cual pretende resolverla.

Por ejemplo, la utopía en el propósito de los protagonistas (la cierva y los gusanos) de tratar de evadir, o hasta de invertir leyes de la naturaleza -no favorecedoras a ciertas especies dentro de la cadena alimenticia-, está presente en los minicuentos "La cierva y la leona» y, justamente, en la obra "Cadena alimenticia». El caso insólito del contrapropósito de los pájaros que logran matar a su cazador en "Visita de pésame», así como en "Ojo por ojo», representa la utopía en la cual se empeña con ahínco un viejo científico, de índole sociolaboral: ganar un 
Premio Nobel; premio que sí gana, en cambio, su objeto de estudio: un microbio. Propósitos y contrapropósitos utópicos al interior de la narración, que pueden o no cumplirse.

b) En contraposición, Ilamo propósitos distópicos o antiutópicos a aquellos que obedecen a objetivos indeseables, invirtiendo todo lo que se percibe al interior de una narración como un ideal de ser y hacer en la naturaleza y en lo social. Por ejemplo, tratar de ir en contra del instinto de autoconservación de la vida ("Celebración»), en contra del ideal de preservación de los humanos de otras especies (los pájaros en «Visita de pésame») o de un orden en la comunidad humana: inversiones lingüísticas para generar confusión en el pensamiento colectivo y perpetuarse en el poder (el monarca en "Los confusos»), o del propósito distópico de intentar arrebatar las pertenencias ajenas, que se opone al ideal de vivir de los ingresos generados por el propio trabajo («Robo»).

\section{Medios}

Los protagonistas trazan, o se les presenta al azar, un medio, o varios, a manera de ayudantes o elementos utensiliares para llevar a cabo su propósito, que pueden ser inmateriales o materiales.

En su medio inmaterial:

1) La dimensión volitiva del protagonista se puede ejercer de manera instrumental a través de la argumentación o de la persuasión, o ambas alternativas, especialmente cuando, para llevarse a cabo el propósito, se depende de otro u otros personajes.

En el caso de la persuasión, puede ejecutarse, por ejemplo, a través de: a) coacción, mediante violencia física o psicológica ejercida sobre otros para obligar a decir o hacer algo contra su voluntad; b) apelación a emociones intersubjetivas; c) pacto, contrato o acuerdo entre dos o más partes.

2) El medio de ejecución del propósito de un protagonista puede presentarse también a través de una decisión, sin depender de otros personajes, para intentar llevar a cabo la 
realización de un cometido. No es el caso de los casos analizados, pero existe esta posibilidad, por ejemplo, en el minicuento titulado «Escape», del venezolano Luis Barrera Linares (1951)².

En cuanto a medios materiales o físicos para cumplir un propósito, pueden ser, por ejemplo, a través de espacios, personas, animales, cosas como armas, bebidas y sus efectos..., para facilitar el propósito.

El o los medios para que el protagonista lleve a cabo un propósito suelen coincidir con el nudo y las peripecias de la narración, o pueden revelarse en la situación final de un minicuento.

Así, en "Los confusos», una vez el rey se propone perpetuarse en el poder a través de una escuela de la confusión, decide dentro del nudo de la narración utilizar la persuasión en la modalidad más drástica, la coacción frente a los demás, cambiando el significado de las palabras en su reino: "-De ahora en adelante -explicó a sus ministros- vamos a cambiar el significado de las palabras. A la noche la llamaremos guayaba, a la golondrina la llamaremos mar, al toro lo llamaremos piedra, al rey lo llamaremos gafas y así hasta completar un nuevo idioma" (Kremer 14).

Y dentro de las peripecias:

Los ministros se pusieron a trabajar y crearon, al cabo del tiempo, un diccionario nuevo.

Todos los niños fueron obligados a prepararse en la nueva escuela.

Cuando estuvo lista la primera generación el rey construyó una nueva ciudad y envió allí a hombres y mujeres (Kremer 14).

Se generan una serie de novedades con medios útiles de índole material para conseguir el propósito: los ministros, inducidos por el monarca, son los que introducen el nuevo diccionario, gestionan la nueva escuela y ciudad para las nuevas generaciones de confusos.

El protagonista en "Ojo por ojo», "un viejo científico", para su propósito de obtener el Premio Nobel de microbiología, y dentro del nudo de la narración, "se dio a la tarea de observar a través del microscopio todos los detalles de la vida de un microbio" (Sánchez Juliao 111). De

\footnotetext{
2 Este minicuento de Barrera Linares está comprendido en su colección titulada En el bar la vida es más sabrosa (1980), seleccionado en una antología de Violeta Rojo (45). La narración comienza así dentro del propósito o detonante de escape del protagonista: "La gitana le presagió que moriría picado por un alacrán. De una vez el hombre decidió marcharse a un país de frío eterno" (Rojo 45). Y continúa el minicuento...
} 
esta manera, los medios físicos que utiliza son: los ojos y su sentido de la observación a través del microscopio, y el microbio, objeto de estudio.

En "La cierva y la leona», como sorpresa en el nudo de la narración y dentro de las peripecias, la protagonista, la cierva, concibe un medio para llevar a cabo su propósito a través de un espacio particular: la taberna y, en su contexto, la bebida (whisky) y la invitación para que la leona pruebe una ensalada, tratando de iniciarla en el cambio de su propensión carnívora por la herbívora. La cierva logra un "pacto» con la leona de no agresión por medio de la persuasión en la modalidad de diálogo y apelando, ante todo, a las emociones de su interlocutora (la leona), en una combinación de medios materiales e inmateriales para obtener su propósito:

Y sucedió que la leona le aceptó el trago y se fueron a la taberna y ustedes saben que una copa de licor siempre trae otra y helas allí bebiendo toda la tarde ese sábado. La cierva llorando por los hijos perdidos y la leona consolándola, pidiendo servilletas para limpiar las lágrimas de la madre. Y a la cierva se le ocurrió una idea genial: pidió dos ensaladas con bastante pasto, aderezada con hojas tiernas y sazonada con perejil y cilantro. "Pruebe usted, señora leona", dijo, "es deliciosa". La leona hizo un gesto de desagrado e iba a pedir una porción de carne, pero por consideración decidió comer la ensalada. Y helas allí bebiendo y comiendo, secreteándose sobre amores y riendo y gozando. La leona dijo que la ensalada de verdad estaba buena y que iba a llevar varias para que la [sic] probaran las otras leonas, los dos leones y los leoncitos que estaban esperándola para comer. Y a la cierva se le hizo un nudo en la garganta, un nudo de felicidad que tuvo que deshacer con otro vaso de whisky, y las dos entendieron en esa noche de luna llena que era posible, por fin, convivir en paz, y se abrazaron y sellaron un pacto de no agresión y para celebrar pidieron otro trago y otro, hasta que la cierva, borracha, cayó sobre la mesa.

¿Y era ético para la leona dejar a su nueva amiga allí, con las amenazas y peligros de hoy en día? "No, señor", se dijo y cargó a la cierva para llevarla hasta el pastizal. Y se fueron por ese camino, tambaleándose, cantando Pueblito viejo y otras canciones. Y la gente animal (jirafas, cocodrilos, cebras y otros) se maravillaban al ver semejante escena (Kremer 18-19).

El minicuento "Cadena alimenticia» no posee una estructura quinaria con peripecias, así que, desde su punto de partida y a través de un nudo de la narración, aparece el "contrato» 
como factor de persuasión de los gusanos con las zorras, para que actúen como guardaespaldas y cumplan el propósito de no ser devorados. Las zorras son, así, el medio físico y el contrato el medio inmaterial, para el propósito de los gusanos.

En el caso de «Visita de pésame», con solo dos elementos narrativos, desenlace y situación final, sabemos que el propósito de Salvador fue "a merced de su ojo implacable con la cauchera de ocho líneas" (Agudelo Duque 25), mientras que el contrapropósito, como reacción de los pájaros, se llevó a cabo con un instrumento corporal: sus picos.

Recuerdo que la noche del velorio, como a las once, tal vez más tarde, entró por la puerta un afrechero. Con saltos cortos y mirando rápido y nerviosamente a los circunstantes, voló al fin sobre el ataúd de tablas pegadas a clavo y martillo. Lo recorrió de arribabajo y de izquierderecha. Se detuvo un momento en el diminuto ventanal puesto ahí como una ojiva o un espejo para mirar al otro lado del infinito. Reconoció los rasgos, el ojo negro, grande, profundo, por donde entró la agonía. Agitó las alas y silbó su canción de todas las mañanas. Después trepó a la solera y se perdió en el agujero más grande de la noche por el agujero más pequeño de la casa (Agudelo Duque 25).

Y en «Robo», el medio físico para que el ladrón trate de conseguir su propósito de hurtar el bolso de una mujer se presenta en las peripecias y en el desenlace de la narración, tras el hecho de que, cuando empezó a correr con el bolso, la mujer tiró de la correa, y:

El hombre cayó de espaldas, pero de inmediato se levantó con un puñal en la mano y de una vez le tiró un navajazo que ella esquivó y, enseguida, asiéndolo por el hombro, aprovechando el impulso del otro, le volteó el brazo hacia la espalda y lo empujó de una patada. Desde el suelo la miró. La mujer se arreglaba la blusa y se acomodaba el bolso. De nuevo el hombre se levantó y se cuadró en posición de boxeador. Ella hizo un gesto de desagrado, se atravesó sobre el pecho el bolso y esperó. Le lanzó un puño al rostro y lo esquivó, luego otro y también lo esquivó. El ladrón retrocedió dos pasos y se puso a dar saltos, adelante, atrás, con los puños al pecho. La mujer lo esperó y cuando se acercó le pegó una trompada. Ya iba a marcharse, pero sintió la embestida a sus espaldas y con sólo dar un paso a un lado el ladrón siguió de largo en una carrera que lo alejó unos tres metros. Vio el puñal y lo levantó. "Ahora sí", le dijo, "perra asquerosa". Se acercó y empezó a pasárselo de una mano a otra, moviéndose rítmicamente, quitándole espacio. La mujer 
retrocedió mientras lo miraba a los ojos. "Dame el bolso", gritó. Dijo no con la cabeza y el hombre se adelantó lanzándole navajazos al pecho y al vientre. Retrocedió otro paso y cuando el puñal pasó cerca del estómago le pegó con la palma abierta un golpe en la frente. Enseguida le cogió la mano y en un solo movimiento la haló hacia el cuello. El ladrón cayó de rodillas. Soltó la navaja y con las dos manos se cubrió la herida. La mujer lo rodeó, se paró frente a él, vio la sangre que primero marcó una línea roja y luego el borbotón que le bañaba la camisa. Entonces le pegó una patada en el rostro y el ladrón cayó (Kremer 61-62).

Los medios del ladrón para cumplir su propósito son la persuasión por coacción a través del intento de violencia corporal (puñal, "posición de boxeador", "puño al rostro", "navajazos al pecho y al vientre"), la violencia psicológica y la intimidación mediante amenazas e insultos ("Ahora sí...", "perra asquerosa"), y órdenes ("Dame el bolso', gritó").

En «Celebración», a pesar del balance positivo de su vida y del hecho de que Saúl sintiera que su vida estaba "amortizada», justo en el instante que quiso suicidarse, este posterga su intención, y el nudo y las peripecias de la narración se presentan así:

Saúl, de temperamento alegre y emotivo, a punto de saltar tuvo una singular idea: convocar a todos sus amigos para una gran fiesta en el día previsto en que habría de despedirse del mundo a su manera. Entre escépticos y divertidos, sus amigos se apuntaron a la ocasión. Se abrieron botellas, se improvisaron discursos y entre fraternales abrazos se celebraron la amistad y la camaradería (Orozco 38).

En este minicuento, los medios materiales e inmateriales que utiliza Saúl para lograr su propósito de suicidio son la persuasión, apelando a las emociones de sus amigos para su asistencia en el día señalado, y las botellas de licor dentro de lo concebido como una celebración, en razón a su temperamento «alegre y emotivo».

\section{Imprevisto}

Surge luego un imprevisto, una súbita ocurrencia de último momento o suceso impensado que sortea la no realización del propósito de un protagonista, y que marca la máxima tensión y suspenso en la narración, coincidiendo, generalmente, con el desenlace en ciertos minicuentos. 
Ese imprevisto se suele indicar en términos temporales en la narración, connotando años, días o breves minutos: "Con el tiempo...", "Más tarde...", "Al cabo del tiempo...", "En último momento...", "Al acercarse en la noche...". Registros temporales que aquí se enfatizan en cursiva en los minicuentos.

De este modo, en «Los confusos» surge el imprevisto de la guerra como signo de rebeldía y final contrapropósito de las víctimas, ante la coacción del rey en su imposición de cambiar el significado de las palabras en su reino:

Con el tiempo, las siguientes generaciones confusas declararon la guerra. Sus ejércitos se tomaron la ciudad, entraron a palacio y pusieron preso al rey. El jefe dijo:

- Gafas, por principio te basamos en el plato torcido. ¡Te disfrazamos el ajedrez por tus colas del caucho! (Kremer 14-15).

En el caso de "Ojo por ojo», un fulminante imprevisto precipita el desenlace: "Más tarde el científico se enteró de que, mirando hacia arriba y observándolo a él, tanto aprendió el microbio, que ganó sin gran esfuerzo entre su raza el premio mundial de oftalmología" (Sánchez Juliao 111).

En tanto que en "La cierva y la leona» se trata de una súbita ocurrencia de la leona, quien carga ya borracha a la cierva: "Se le ocurrió a la leona, en último momento, presentar su nueva amiga a la manada. '¿Por qué no?', se preguntó, 'si hasta comadres vamos a ser'” (Kremer 1920).

Y en "Cadena alimenticia», lo temporal se evidencia en el pacto de los gusanos con las zorras de actuar como guardaespaldas para no ser devorados por los pollos y las gallinas, "al cabo del tiempo, estas aves murieron de hambre, por falta de alimento" (Laverde Sánchez 118). Y no previeron los gusanos lo que será enseguida su situación final.

En «Visita de pésame», lo impensado se encuentra en el desenlace al comienzo de la narración, ya referida: "A Manuel Salvador lo mataron los pájaros" (Agudelo Duque 25). Ya el hecho está consumado dentro del contrapropósito de los pájaros de no dejar que este personaje, con irónico apellido de "Salvador», los siguiera eliminando por medio de su cauchera.

En «Robo», lo inesperado en el propósito del ladrón se suscita en las peripecias y el desenlace para contrarrestar sus acciones, a fin de conseguir hurtar un bolso: hábiles y eficaces 
maniobras corporales (esquivar, empujar de una patada, golpe en la frente, trompada, paso a un lado...), y la actitud mental y psicológica (astucia, valor, seguridad, firmeza, tranquilidad) por parte de su «víctima», una mujer.

Y, finalmente, en «Celebración»:

Al acercarse en la noche el plazo estipulado, las especulaciones se disparan. Alguien asegura que Saúl esconde en su boca una cápsula de cianuro. Otros apuestan por el salto al vacío o por un profundo corte en las muñecas. Hay conjeturas acerca de una ingestión de tranquilizantes. Algún amago de desmayo se combina con susurros, ayes y secretos al oído. Todos los ojos se clavan en los movimientos de Saúl quien, medio borracho y feliz, olvida sus tratos con la muerte gracias a los ojazos y el redondísimo trasero de una morena (Orozco 38).

\section{Inversión}

Tras la ocurrencia de última hora o circunstancia no prevista, viene una completa inversión de la situación que conduce a la imposibilidad o frustración del propósito del protagonista, y que suele precipitar su muerte; justamente, cuando se ha partido del propósito de muerte, lo fortuito lleva a la intención contraria: prolongar la vida.

Así, en "Los confusos», luego del imprevisto para el monarca de la insubordinación a través de la guerra, una vez apresado por parte del líder de la nueva generación formada en la escuela de la confusión lingüística y del pensamiento, sucede lo siguiente: "Al escuchar a su jefe los hombres confusos llevaron al rey a la plaza y lo decapitaron" (Kremer 15). En este sentido, no logra perpetuarse más en el poder según su propósito.

En el caso de «Ojo por ojo», la situación final muestra que: "El viejo científico nunca llegó a Nobel. Murió de envidia cuando observó en el microscopio la ceremonia y la premiación de su 'objeto de investigación'” (Sánchez Juliao 111).

En cuanto a «La cierva y la leona», tras la repentina ocurrencia de la leona de presentar a la manada a su nueva amiga, la cierva -dice el narrador-, en su estado de borrachera e inconsciencia: " (...) cargó a su amiga hasta la casa donde leones, leonas y leoncitos devoraron a la cierva mientras alababan el buen sabor de la carne curtida en alcohol" (Kremer 20). Así, 
se reafirma dentro de las leyes de la naturaleza la cadena alimenticia de carnívoros frente a herbívoros.

Precisamente, igual que en "Cadena alimenticia», tras el hecho de morir las aves de hambre, "las zorras se vieron obligadas a comer gusanos" (Laverde Sánchez 18).

Y en «Visita de pésame», ya el desenlace con el que comienza la narración nos indica que la acción de Manuel Salvador de matar a los pájaros se vio imposibilitada en el momento en que estos le impidieron seguir ocasionándoles su muerte.

En el caso del minicuento «Robo», una vez que la mujer sometió al ladrón al caer con una herida probablemente mortal en el cuello, "antes de irse le vio el bulto en el bolsillo de atrás. Le colocó un pie en la espalda mientras le sacaba la billetera. La guardó en el bolso y siguió su camino" (Kremer 62). Por tanto, se da, igualmente, una completa inversión del propósito del ladrón.

Esto sucede también en «Celebración», dentro de la situación final, cuando "pasada la media noche, profundamente decepcionados y con malas caras, los invitados dando un portazo se retiran" (Orozco 39).

Partiendo de las pautas compositivas o estructurales aquí examinadas: propósito - medio - imprevisto - inversión, son observables ciertas características comunes y diferenciales de cada uno de estos parámetros, que conducen hacia funciones y efectos de la inversión de propósitos en los protagonistas de los minicuentos, abordados a continuación siguiendo la muestra ejemplificativa.

\section{Funciones de la inversión de propósitos}

Una de las características de la inversión del propósito de los protagonistas es que en la mayoría de los minicuentos amenaza un orden natural o instituido. En nuestros ejemplos, esto es observable tras la dinámica predador-presa y el intento fracasado ("Cadena alimenticia», "La cierva y la leona») o no ("Visita de pésame») de evadir esta correlación, y al intentar acabar con la propia vida ("Celebración»); al ir en contra de un orden lingüístico y mental ("Los confusos»); al propender más hacia el ego que hacia el bien común ("Ojo por ojo»); o al estar en contravía de un orden socioeconómico en cuanto a la adquisición de bienes («Robo»).

El propósito protagónico en estos minicuentos transgrede algún límite, y se plantea, en algunos casos, con una intención utópica y, en otros, bajo una acción decididamente distópica, 
que instaura una realidad negativa. En cualquier caso, se trata de intenciones que son despropósitos, en el sentido de algo inconveniente, a veces un verdadero dislate o desatino que aboca hacia un mundo al revés.

Son propósitos que plantean, en algunos momentos, un problema a las individualidades o colectividades utilizadas por el protagonista como instrumento para llevar a cabo su objetivo. Estas entidades, por lo tanto, son las que, justamente, terminan frustrando el propósito, debido a que van en contra de un orden que, de alguna forma, violenta su ser o que va en contravía de un estado de cosas. Son los medios utilizados los que ofrecen una resistencia u obedecen, simplemente, a sus propios instintos de sobrevivencia, intentando salvarse ante la amenaza de un mundo disparatado que los propósitos protagónicos llevan tras de sí y que abocan hacia una crisis en la individualidad o en la colectividad.

En este sentido, tras los propósitos protagónicos fundados en algún grado de disfuncionalidad, insensatez y disparate, hay una contracorriente -generalmente con carácter punitivo- que tiende hacia la insubordinación, revolución, revancha, venganza y necesidad de un cambio de mentalidad. Esos contrapropósitos tienen la función de interpelar hacia la sensatez o hacia la imposibilidad o lo insostenible en la intención contranatura o en contravía de una determinada realidad instituida.

Es así como, tras la problematización que el propósito implica y su irrealización o suspensión final, se va la vida del protagonista en estos minicuentos: decapitación del rey («Los confusos»), devoramiento de la cierva por parte de una manada de leones ("La cierva y la leona») y de los gusanos por cuenta de las zorras ("Cadena alimenticia»), muerte a picotazos del cazador Manuel Salvador por parte de los pájaros que él perseguía y eliminaba ("Visita de pésame»), herida mortal al ladrón a manos de una mujer que iba a ser robada, en un trastocamiento entre víctima y victimario ("Robo»); y, ya sea literal o simbólicamente, muerte por envidia de un científico ("Ojo por ojo»), que aboca hacia un tipo de narración con ciertas constantes en estos minicuentos.

Exceptuando el caso del protagonista de "Celebración», todos han tenido la intención de prolongar la vida: sea en lo biológico (la cierva en el minicuento "La cierva y la leona», los gusanos en "Cadena alimenticia» y los pájaros en "Visita de pésame»), en lo económico (el ladrón y la propia víctima en «Robo»), en el ejercicio del poder (el monarca en «Los confusos») o en los honores (el científico en «Ojo por ojo»). 
Hay un sino trágico en la gran mayoría de estos minicuentos, a través de los propósitos de los protagonistas, con una tensión entre la pulsión de vida (eros) y de muerte (thánatos), triunfando esta última bajo la tendencia a eliminar al protagonista y su objetivo. De esta forma, se da un trasfondo aleccionador dentro de las funciones, en este caso, de la inversión de propósitos de los protagonistas, que en algunos minicuentos (p. ej., "La cierva y la leona», "Cadena alimenticia») puede provenir del origen didáctico de las fábulas, en donde los animales piensan y hablan, aunque sin explicitar ahora su tradicional moraleja situada ya sea al comienzo (promitio) o al final (epimitio), y evidenciando el carácter proteico o híbrido entre géneros literarios, que tanto se ha observado en los minirrelatos ${ }^{3}$.

De todos modos, en el resto de los minicuentos aquí seleccionados, sin reminiscencia de fábula, aún existe, por igual, una función edificante y crítica que se sintetiza en alguna paremia vertida implícitamente en proverbios, dichos y refranes: "Ojo por ojo, diente por diente», aludido parcialmente en el título intertextual del minicuento "Ojo por ojo»" o de manera más implícita en los hechos de la narración en «Robo», en la que resuena también, de algún modo, el refrán exhortativo, "El malo, él mismo se mata»; al igual que: "Salió por lana y volvió trasquilado», "Le salió el tiro por la culata», "Víctima de su propio invento», que resuenan en "Los confusos», "La cierva y la leona», "Cadena alimenticia» y en "Visita de pésame», donde, inclusive, resulta irónico que se consuma el hecho de ese "Cuándo se había visto que los pájaros le tiran a las escopetas» o, en este caso, al cazador. Y se plantea, igualmente, el mecanismo inversor y el aleccionamiento en situaciones tales como: el cazador-cazado (p. ej., "Visita de pésame»), el observadorobservado (p. ej., "Ojo por ojo») o el ladrón-robado (p. ej., "Robo»).

La inversión de propósitos de los protagonistas conduce así también, en el nivel semántico, hacia la función en estos minicuentos, ya sea de:

- Sensibilizar acerca de la indefensión (gusanos en "Cadena alimenticia») y el traumatismo ("La cierva y la leona»), al introducir el punto de vista de las presas frente a los

\footnotetext{
3 Rosa Tezanos-Pinto (168) observa que, aunque Violeta Rojo (El minicuento: ese des-generado 45) y Lauro Zavala (112) anotan que los microrrelatos actuales se suelen nutrir de las fábulas y de los bestiarios, lo hacen sin moraleja; no obstante, incide en el hecho de que la colección titulada $A B C$ de las microfábulas (2009), de Luisa Valenzuela, sí contiene explícitamente la moraleja y el consejo, evitando así el uso de generalizaciones.

4 Sobre la importancia de los títulos en los minicuentos, tipología y características, véase, por ejemplo, a Pujante Cascales (245-259).
} 
depredadores en la cadena trófica, aunque admitiendo de manera realista la inutilidad de tratar de evadir las leyes de la naturaleza.

- Sancionar el propósito de la gratuita mortandad de otros seres de la naturaleza (p. ej., los pájaros), por parte de ciertos individuos del género humano (Salvador en «Visita de pésame»). Sensibilización que surge con fuerza creciente desde el siglo XX hasta nuestros días, con el movimiento ecologista y proteccionista hacia los animales y la amenaza de extinción.

- Desaprobar el propósito de suicidio («Celebración»), en el contexto de la consonancia extrínseca con un incremento mundial entre los siglos XX y XXI.

- Disentir, igualmente, del propósito distópico de la tiranía en la política y su injerencia en la confusión del pensamiento en la vida individual y colectiva de las naciones bajo esta circunstancia ("Los confusos») 5 .

- Trastocar e ironizar la situación victimario-víctima, bajo la posibilidad, por ejemplo, del robador-robado (p. ej., «Robo»). Esto revive, implícitamente, en el mundo contemporáneo, entre otras posibilidades interpretativas, la antigua y polémica ley del talión, establecida, durante el siglo V a. C., en las XII Tablas, que en la Biblia se conoce como «Ojo por ojo, diente por diente» ${ }^{6}$.

- Vulnerar la jerarquía de valores en cuanto a la orientación individual hacia la gloria y el ego profesional, más que, quizá, el conocimiento desinteresado y científico a beneficio de la colectividad («Ojo por ojo»).

Se sortea así, a través de la inversión de propósitos de los protagonistas, el sensibilizar, sancionar, desaprobar, disentir, trastocar, ironizar y vulnerar una jerarquía de tendencias y de contravalores. La inversión final contraviene el propósito protagónico, que es, a su vez,

\footnotetext{
${ }^{5}$ Es de señalar que, aunque el autor del minicuento "Los confusos», Harold Kremer, contextualiza esta obra en un período histórico de siglos atrás, el tema de la tiranía es igualmente sensible y en boga en el contexto mundial más cercano: gobiernos totalitarios en Rusia (Stalin), China (Mao); en Europa, nazismo, fascismo, nacionalismo, franquismo; en Irak (Hussein); en Latinoamérica, con una extensa lista de dictadores a lo largo del siglo XX: en Nicaragua, la familia Somoza (desde la década del treinta al setenta); en Cuba, Fulgencio Batista, destituido por Fidel Castro (años cincuenta); lo mismo que en Colombia, con Gustavo Rojas Pinilla (a mediados de ese siglo); en Brasil, Humberto Branco, Artur da Costa e Silva, Emíllio Garrastazu Médici, Ernesto Geisel y João Baptista Figueiredo (entre los sesenta y los ochenta); en Ecuador, Guillermo Rodríguez Lara (década de los setenta); en Chile, Augusto Pinochet (entre los años setenta y noventa); en Argentina, Rafael Videla, Roberto Viola, Leopoldo Galtieri y Reynaldo Bignone (entre las décadas de los setenta y ochenta); y así, igualmente, en México, Honduras, Guatemala, Panamá, Venezuela, Bolivia, Perú, Uruguay, Paraguay, República Dominicana...

${ }^{6}$ Para una introducción sobre la ley del talión, véase, por ejemplo, García-Hernández.
} 
transgresor de un orden; responde con una subversión a la transgresión del propósito. Por ende, se trata de minicuentos cuyo principio activo es el de la transgresión como problematización y, a la vez, como solución. El procedimiento de la inversión actúa a tope y es decisivo para ambas funciones: problematizar y resolver. Se trata de una inversión de la inversión en una verdadera lógica conjuntiva, coincidentia oppositorum, o diálogo de ejercicios contrarios dentro de las funciones de un mismo procedimiento.

La inversión es, por tanto, una fuerza destructiva y constructora. Instaura el desorden, el caos; pero también la inversión final de las narraciones reinstaura el orden en el mundo creado. La inversión destruye y crea, aunque, si bien es producto de la sinrazón, puede asimismo propiciar nuevamente la cordura y el orden. Guante de doble faz, el procedimiento de la inversión desdobla el mundo creado, lo destruye y lo reconstruye. Si el propósito protagónico amenaza hacia un mundo al revés o, en algunas narraciones, de hecho, lo instaura, la inversión final depone el propósito al eliminar al protagonista, en la gran mayoría de los minicuentos, bajo esta construcción, y convoca nuevamente al orden, a la vez que genera la condición estructural para un final sorpresivo en la narración.

\section{Hlgunas condiciones del efecto de un final sorpresivo}

En el género del cuento, según la observación del formalista Boris Eichenbaum, así como en la anécdota (de donde proviene):

... todo tiende hacia la conclusión. El cuento debe lanzarse con impetuosidad, como un proyectil lanzado desde un avión para golpear con su punta y con todas las fuerzas el objetivo propuesto. Me refiero aquí al cuento de intriga, dejando de lado el cuentodescripción que caracteriza la literatura rusa, así como el "relato directo". Short storyes un término que implica siempre una historia y que debe responder a dos condiciones: dimensiones reducidas y acento puesto sobre la conclusión. Estas condiciones crean una forma enteramente diferente a la novela, tanto en su finalidad como en sus procedimientos.

El papel primordial en la novela lo desempeñan otros factores: la técnica utilizada para demorar la acción, para combinar y soldar los elementos heterogéneos, la habilidad para desarrollar y ligar los episodios, para crear centros de interés diferentes, para conducir las 
intrigas paralelas, etc. Esta construcción exige que el final de la novela sea un momento de debilitamiento y no de esfuerzo; el punto culminante de la acción principal debe encontrarse en alguna parte antes del final. La novela se caracteriza por la presencia de un epílogo: una falsa conclusión, un balance que abre una perspectiva.... Es natural, en consecuencia, que un final inesperado sea un fenómeno muy raro en la novela (si se lo encuentra sólo revela la influencia del cuento): las grandes dimensiones y la diversidad de episodios impiden ese modo de construcción, mientras que el cuento tiende precisamente a lo inesperado del final donde culmina lo que le precede. En la novela al punto culminante, debe suceder una cierta pendiente, mientras que en el cuento es más natural detenerse en la cima que se alcanza. Se puede comparar la novela a un largo paseo por lugares diferentes, que presupone un retorno tranquilo; el cuento a la escalada de una colina, que tiene por finalidad ofrecernos la vista que se descubre desde la altura (151-152).

Esta importancia en el acento final, dentro del género del cuento, es complementada por Eichenbaum, trayendo a colación las observaciones de Robert Louis Stevenson, quien escribía a un amigo en 1891, a propósito de uno de sus cuentos: "El desenlace de una novela no significa nada: se trata sólo de una conclusión (coda), que no es un elemento esencial de su ritmo; pero el contenido y el fin de un cuento son mutuamente carne de la carne y sangre de la sangre desde su comienzo" (ctd. en Eichenbaum 155). Este teórico ruso resalta, sobre este último género literario, la característica de "cuidar particularmente los finales sorprendentes y a construir el cuento en base a un enigma o un error que conserva el papel motor de la intriga hasta el final" (155).

Por su parte, en torno al minicuento, se ha anotado: "El final siempre es importante, inesperado y sorprendente” (Díaz Castañeda y Parra Rojas 9); en el "Manifiesto del minicuento», publicado en la revista Zona de Barranquilla, se observaba que "siempre tiene un final de puñalada" (ctd. en Rojo, Breve manua/25); es común una "resolución asombrosa", donde "para el lector que intuye la ironía en este género, hay indicios que desde el mismo título, las primeras líneas del cuento, lo llevan a una expectación más o menos sorpresiva" (Rodríguez Romero 84). En las anotaciones de Lauro Zavala, los minicuentos "concluyen con una sorpresa" (75). Por su parte, la escritora Ana María Shua comenta: "ese efecto de deslumbramiento que no siempre es inmediato, esos veinte segundos antes del clic que llevan a la comprensión plena" (250). Raúl Brasca se refiere al "efecto de una revelación" final (88); en tanto que Irene Andrés- 
Suárez observa que al autor de minicuentos "no le interesa el desarrollo del conflicto o la construcción minuciosa de los protagonistas y del espacio, sino el momento climático de la historia del personaje", de tal manera que "lo que diferencia al microrrelato del cuento clásico no es tanto la extensión como esa enorme tensión" (177).

Aunque en realidad esta, y otras diferenciaciones que se han presentado entre cuento y minicuento, no son tales, si seguimos, por ejemplo, las observaciones de Eichenbaum en torno a las comparaciones entre novela y cuento. De acuerdo con esto, dentro de las anteriores anotaciones de diversos teóricos sobre el minicuento, la «enorme tensión», el «momento climático», el "final de puñalada», la "resolución asombrosa», la «expectación más o menos sorpresiva», el "efecto de deslumbramiento», o también el «efecto de una revelación», pueden hallarse, igualmente, en el cuento de mayor extensión. Es solo que en el minicuento estos efectos se agudizan, prácticamente, como una consecuencia directa de su estructura drásticamente breve abocada hacia la intensidad; por ende, el final posee una resonancia aún mayor. Pero no se trata de una pauta que distinga de manera rotunda el cuento del minicuento, salvo en cuanto a ese grado de intensidad y contundencia en el efecto final; no por su ausencia en el cuento y su presencia absoluta, a cambio, en el minicuento ${ }^{7}$.

Sin embargo, lo fundamental no es observar aquí esta característica del final del cuento y su acentuación en el minicuento, sino su inscripción dentro de unas ciertas constantes, en este caso, en las pautas discernidas para con el tipo de minicuentos en los que se plantea una inversión de propósitos en protagonistas, y, básicamente, en este horizonte particular, las condiciones con respecto al surgimiento de un final sorpresivo.

En efecto, en los minicuentos aquí seleccionados, que se estructuran a través de un propósito protagónico, es entre las dos últimas pautas narrativas de la secuencia propósito medio - imprevisto - inversión donde se genera la característica del final sorpresivo. En el imprevisto y la inversión se sortea, precisamente, lo impensado, lo inesperado; oblitera el tiempo y hace girar sobre sí mismo todo lo recorrido como vano y perdido, mediante la sublevación ante el propósito del protagonista, que va a pasar por un fulminante cortocircuito.

7 El crítico David Roas se encarga de debatir otras de las supuestas diferenciaciones que se han argumentado entre cuento y minicuento (47-76). Por su parte, Lagmanovich alude a otros tipos de finales, no exclusivamente por inversión, sino también por repetición y por epifanía, tanto en minicuentos como en el género de la poesía (101-102). 
Específicamente en este tipo de narraciones, la tensión entre propósito protagónico y medio utilizado encuentra su salida en el imprevisto que lleva hacia la inversión del propósito y su consecuencia para con la suerte final del protagonista. Ese imprevisto, en gran medida, no es gratuito, pues se desata gracias a tres factores básicos, ejemplificados aquí en la colección de minicuentos seleccionados:

1. El establecimiento de contrapropósitos, con dos posibilidades:

a) En los casos en que se plantea la dinámica victimario-víctima/s de un propósito, se da la condición prácticamente dentro de una correlación causa-efecto, para la generación de estados disfóricos (por ejemplo, indignación e ira) y sus posibles acciones consecuentes (resistencia y sublevación) por parte de las víctimas, configurándose un contrapropósito.

Encontramos así a toda una comunidad en "Los confusos», que, en su desconcierto, ira y resistencia final, declara la guerra, apresa y mata al monarca del cual es víctima en su propósito de perpetuarse en el poder a través de una escuela de la confusión lingüística y mental. En la naturaleza, se ubican los pájaros que son atacados y que se insubordinan y vengan de manera insospechada y radical en "Visita de pésame». Y, a nivel individual, se encuentra la mujer indignada y hábil que se niega a dejar que su bolso vaya a parar a manos de un ladrón, en el minirrelato «Robo».

b) También los contrapropósitos pueden generarse a través de mayores competencias de alguno de los medios utilizados por el protagonista en su propósito. Tenemos, en el minicuento «Ojo por ojo», al microbio -objeto de observación y medio de un científico para tratar de obtener un Premio Nobel de microbiología-, que resulta ser más competente en la observación que el científico, quien acaba por facilitarle al hábil microbio ganar, para sí y en beneficio de su comunidad, un premio mundial en oftalmología entre su especie.

2. El imprevisto y la condición de un final sorpresivo puede generarse, igualmente, debido a las mismas caracterizaciones de los personajes, que resultan ser adversas en cuanto a la realización de un propósito determinado.

Por ejemplo, dentro de los atributos que se sortean en los personajes de «La cierva y la leona» están la inocencia y la ingenuidad de ambas, que en la fase de su contacto les facilita ser amigas; pero donde, igualmente, estas cualidades contribuyen a conducir hacia la muerte de la cierva como protagonista, entregada a su suerte ante las acciones de una leona carente de malicia y fuera de sí como para prever la conducta instintiva de su manada. 
3. Se presentan también ciertos medios utensiliares que pueden llevar a condiciones de vulnerabilidad en los protagonistas y abocar hacia la inversión de propósitos y el efecto final sorpresivo de la narración.

Ilustrativamente, en "La cierva y la leona», el licor, estrategia de acercamiento de la cierva hacia la leona -además de causa o consecuencia de un estado de alegría y de hilaridad ante sus avances de amistad con la leona-, la lleva al emborrachamiento y a quedar a expensas de la ingenua voluntad de la leona. En "Celebración», también Saúl queda, en su caso, "medio borracho y feliz", lo cual contribuye a olvidar "sus tratos con la muerte", conjuntamente ante la presencia y las reacciones emotivas hacia "los ojazos y el redondísimo trasero de una morena" (Orozco 38). De esta manera, ciertos elementos utensiliares pueden ir más bien en contra del protagonista y contribuir a la inversión de su propósito.

Tras estos tres factores (contrapropósitos, caracterización de personajes y vulnerabilidad ante elementos utensiliares), ya sea independientes o combinados entre la apertura y el cierre de los minicuentos traídos a colación, hay un completo desdoblamiento, un punto de quiebre que frustra el propósito del protagonista, conduce directamente hacia su muerte, en la gran mayoría de las obras, y genera algunas de las singulares condiciones para un final sorpresivo aunado a la ironía y a la paradoja.

Se establecen así peculiaridades narrativas en la construcción de ciertos minicuentos, bajo el procedimiento de la inversión, particularmente dentro de su tipología, la inversión de propósitos en protagonistas, y su función y efecto.

\section{Referencias}

Agudelo Duque, Adalberto. "Visita de pésame". Tercera antología del cuento corto colombiano. Comps. Guillermo Bustamante Zamudio y Harold Kremer. Cali: Deriva, 2017. 25. Impreso.

Andrés-Suárez, Irene. Estrategias del microrrelato para ahorrar espacio textual. La minificción en el siglo XXI: Aproximaciones teóricas. Ed. Henry González Martínez. Bogotá: Universidad Nacional de Colombia, 2014. 176-188. Impreso.

Barrera Linares, Luis. "Escape”. En el bar la vida es más sabrosa. Caracas: UPEL, 1980. Impreso. 
Barrera Linares, Luis. "Escape". La minificción en Venezuela. Comp. Violeta Rojo. Bogotá: Universidad Pedagógica Nacional, 2004. 45. Impreso.

Bajtín, Mijaíl. La cultura popular en la Edad Media y en el Renacimiento. El contexto de François Rabelais. Trad. Julio Forcat y César Conroy. Madrid: Alianza, 1990. Impreso.

Brasca, Raúl. Dos décadas con la microficción: descubrimientos y redescubrimientos. La minificción en el siglo XXI: Aproximaciones teóricas. Ed. Henry González Martínez. Bogotá: Universidad Nacional de Colombia, 2014. 86-98. Impreso.

Bustamante Zamudio, Guillermo y Harold Kremer. Tercera antología del cuento corto colombiano. Cali: Deriva, 2017. Impreso.

Díaz Castañeda, Rodrigo y Carlos Parra Rojas. Breve teoría y antología sobre el minicuento latinoamericano. Neiva: ACE Samán editores. Universidad Surcolombiana, 1993. Impreso.

Diccionario de la lengua española. Vols. 6 y 10. España: Real Academia Española, 2001. Impreso.

Eichenbaum, Boris. "Sobre la teoría de la prosa". Teoría de la literatura de los formalistas rusos. Comp. Tzvetan Todorov. Trad. Ana María Nethol. México: Siglo XXI Editores, 1980. 147-157. Impreso.

García-Hernández, Benjamín. "La ley romana del talión y su base correlativa: antigüedad e innovación". Emérita, Revista de Lingüística y Filología Clásica. LXXXV. 2. 2017: 223239. Digital.

Kremer, Harold. "Los confusos", "La cierva y la leona", "Robo". El combate. Cali: Deriva, 2004. 14, 18, 61. Impreso.

Lagmanovich, David. Abismos de la brevedad. Seis estudios sobre el microrrelato. México: Universidad Veracruzana, 2013. Impreso.

Laverde Sánchez, Gustavo. "Cadena alimenticia". Cuentos cuadrados. Bogotá: Gráficas Jair, 2005. 21. Impreso.

Orozco, Felipe. "Celebración”. Seré breve. Calarcá: Cuadernos Negros, 2014. 38-39. Impreso. Pujante Cascales, Basilio. "Minificción y título". La era de la brevedad. El microrrelato hispánico. Actas del IV Congreso Internacional de Minificción. Universidad de Neuchâtel, 6-8 de noviembre de 2006. Eds. Irene Andrés-Suárez y Antonio Rivas España: Menoscuarto ediciones, 2008. 245-259. Impreso. 
Roas, David. "El microrrelato y la teoría de los géneros". La era de la brevedad. El microrrelato hispánico. Actas del IV Congreso Internacional de Minificción Universidad de Neuchâtel, 6-8 de noviembre de 2006. Eds. Irene Andrés-Suárez y Antonio Rivas. España: Menoscuarto ediciones, 2008. 47-76. Impreso.

Rodríguez Romero, Nana. Elementos para una teoría del minicuento. $2^{a}$ ed. Tunja: Universidad Pedagógica y Tecnológica de Colombia, 2007. Impreso.

Rojo, Violeta. Breve manual para reconocer minicuentos. Caracas: Universidad Simón Bolívar, 1996. Impreso.

Rojo, Violeta. El minicuento: ese des-generado. Revista Interamericana de Bibliografía. 46. 1-4. 1996: 39-47. Impreso.

Ruiz Sánchez, Marcos y Mariano Valverde Sánchez. "Los adynata en Virgilio". Simposio Virgiliano: conmemorativo del bimilenario de la muerte de Virgilio. Murcia: Universidad de Murcia, 1984. 511-519. Impreso.

Sánchez Juliao, David. "Ojo por ojo”. El arca de Noé. Bogotá: Tercer Mundo, 1976. 111. Impreso.

Serrano Orejuela, Eduardo. "Prólogo: Minicuentos y gradientes de narratividad". Tercera antología del cuento corto colombiano. Comps. Guillermo Bustamante Zamudio y Harold Kremer. Cali: Deriva, 2017. 1-23. Impreso.

Shua, Ana María. "La brevedad, técnica y misterio". La minificción en el siglo XXl: Aproximaciones teóricas. Comp. Henry González Martínez. Bogotá: Universidad Nacional de Colombia, 2014. 46-58. Impreso.

Tezanos-Pinto, Rosa. "'ABC de las microfábulas'de Luisa Valenzuela: reflexión y consejo en el texto narrativo". Entre el ojo y la letra: El microrrelato hispanoamericana actual. Eds. Carlos E. Paldao y Laura Pollastri. Estados Unidos de América: Academia Norteamericana de la Lengua Española, 2014. 353-377. Impreso.

Tomashevski, Boris. "Temática". Teoría de la literatura de los formalistas rusos. Comp. Tzvetan Todorov. México: Siglo XXI Editores, 1980. 199-232. Impreso.

Villalba de la Güida, Isabel. "En las fronteras del adynaton: lo imposible como recurso retóricopoético en la elegía latina". Cuadernos de filología clásica. Estudios latinos. 30. 1. 2010: 77-99. Digital. 
Zavala, Lauro. La minificción bajo el microscopio. Bogotá: Universidad Pedagógica Nacional, 2005. Impreso.

\section{ANEXO \\ Minicuentos seleccionados}

\section{«0jo por ojo»}

David Sánchez Juliao

Obstinado en conseguir el Premio Nobel de microbiología, un viejo científico se dio a la tarea de observar a través del microscopio todos los detalles de la vida de un microbio.

Más tarde el científico se enteró de que, mirando hacia arriba y observándolo a él, tanto aprendió el microbio, que ganó sin gran esfuerzo entre su raza el premio mundial de oftalmología.

El viejo científico nunca llegó a Nobel. Murió de envidia cuando observó en el microscopio la ceremonia y la premiación de su "objeto de investigación".

\section{«Los confusos»}

Harold Kremer

El monarca de aquel país, para perpetuarse en el poder, se propuso crear una escuela de la confusión.

-De ahora en adelante -explicó a sus ministros- vamos a cambiar el significado de las palabras. A la noche la llamaremos guayaba, a la golondrina la llamaremos mar, al toro lo llamaremos piedra, al rey lo llamaremos gafas y así hasta completar un nuevo idioma.

Los ministros se pusieron a trabajar y crearon, al cabo del tiempo, un diccionario nuevo.

Todos los niños fueron obligados a prepararse en la nueva escuela.

Cuando estuvo lista la primera generación el rey construyó una nueva ciudad y envió allí a hombres y mujeres.

Con el tiempo, las siguientes generaciones confusas declararon la guerra. Sus ejércitos se tomaron la ciudad, entraron a palacio y pusieron preso al rey. El jefe dijo:

-Gafas, por principio te basamos en el plato torcido. ¡Te disfrazamos el ajedrez por tus 
colas del caucho!

Al escuchar a su jefe, los hombres confusos llevaron al rey a la plaza y lo decapitaron.

\section{«La cierva y la leona»}

Harold Kremer

Lo ideal sería que la leona antes de atacar y devorar al pequeño ciervo, hablara con la madre del animalito y le dijera los motivos del crimen. Quizá la cierva la invitaría entonces a un trago porque tendría mucho de que hablar sobre ese tema, pues ya ha perdido tres ciervitos en las garras de leones, leopardos y otros depredadores. Pensaría la cierva: "Al fin y al cabo las dos somos madres, y hablaríamos de sentimientos y esas cosas". Y sucedió que la leona le aceptó el trago y se fueron a la taberna y ustedes saben que una copa de licor siempre trae otra y helas allí bebiendo toda la tarde de ese sábado. La cierva llorando por los hijos perdidos y la leona consolándola, pidiendo servilletas para limpiar las lágrimas de la madre. Y a la cierva se le ocurrió una idea genial: pidió dos ensaladas con bastante pasto, aderezada con hojas tiernas y sazonada con perejil y cilantro. "Pruebe usted, señora leona", dijo, "es deliciosa". La leona hizo un gesto de desagrado e iba a pedir una porción de carne, pero por consideración decidió comer la ensalada. Y helas allí bebiendo y comiendo, secreteándose sobre amores y riendo y gozando. La leona dijo que la ensalada de verdad estaba buena y que iba a llevar varias para que la probaran las otras leonas, los dos leones y los leoncitos que estaban esperándola para comer. Y a la cierva se le hizo un nudo en la garganta, un nudo de felicidad que tuvo que deshacer con otro vaso de whisky, y la dos entendieron en esa noche de luna llena que era posible, por fin, convivir en paz, y se abrazaron y sellaron un pacto de no agresión y para celebrar pidieron otro trago y otro, hasta que la cierva, borracha, cayó sobre la mesa.

¿Y era ético para la leona dejar a su nueva amiga allí, con las amenazas y peligros de hoy en día? "No, señor", se dijo y cargó a la cierva para llevarla hasta el pastizal. Y se fueron por ese camino, tambaleándose, cantando Pueblito viejo y otras canciones. Y la gente animal (jirafas, cocodrilos, cebra y otros) se maravillaban al ver semejante escena. Se le ocurrió a la leona, en último momento, presentar su nueva amiga a la manada. "¿Por qué no?", se preguntó, "si hasta comadres vamos a ser".

Y cargó a su amiga hasta la casa donde leones, leonas y leoncitos devoraron a la cierva mientras alababan el buen sabor de la carne curtida en alcohol.

\section{«Robo»}

Harold Kremer

El ladrón arrancó el bolso de la desprevenida transeúnte y cuando empezó a correr la mujer tiró 
de la correa. El hombre cayó de espaldas, pero de inmediato se levantó con un puñal en la mano y de una vez le tiró un navajazo que ella esquivó y, enseguida, asiéndolo por el hombro, aprovechando el impulso del otro, le volteó el brazo hacia la espalda y lo empujó de una patada. Desde el suelo la miró. La mujer se arreglaba la blusa y se acomodaba el bolso. De nuevo el hombre se levantó y se cuadró en posición de boxeador. Ella hizo un gesto de desagrado, se atravesó sobre el pecho el bolso y esperó. Le lanzó un puño al rostro y lo esquivó, luego otro y también lo esquivó. El ladrón retrocedió dos pasos y se puso a dar saltos, adelante, atrás, con los puños al pecho. La mujer lo esperó y cuando se acercó le pegó una trompada. Ya iba a marcharse, pero sintió la embestida a sus espaldas y con sólo dar un paso a un lado el ladrón siguió de largo en una carrera que lo alejó unos tres metros. Vio el puñal y le levantó. "Ahora sí", le dijo, "perra asquerosa". Se acercó y empezó a pasárselo de una mano a otra, moviéndose rítmicamente, quitándole espacio. La mujer retrocedió mientras lo miraba a los ojos. "Dame el bolso", gritó. Dijo no con la cabeza y el hombre se adelantó lanzándole navajazos al pecho y al vientre. Retrocedió otro paso y cuando el puñal pasó cerca del estómago le pegó con la palma abierta un golpe en la frente. Enseguida le cogió la mano y en un solo movimiento la haló hacia el cuello. El ladró cayó de rodillas. Soltó la navaja y con las dos manos se cubrió la herida. La mujer lo rodeó, se paró frente a él, vio la sangre que primero marcó una línea roja y luego el borbotón que le bañaba la camisa. Entonces le pegó una patada en el rostro y el ladrón cayó.

Antes de irse le vio el bulto en el bolsillo de atrás. Le colocó un pie en la espalda mientras le sacaba la billetera. La guardó en el bolso y siguió su camino.

\section{«Celebración»»}

Felipe Orozco

Calculando el vacío desde su balcón, el angustiado Saúl observó el trasiego de la calle mucho más abajo y sopesó la caída. Midió también el vacío de su existencia, mas concluyó, que a pesar de todo el balance era positivo. "Mi vida está ya amortizada", pensó.

Saúl, de temperamento alegro y emotivo, a punto de saltar tuvo una singular idea: convocar a todos sus amigos para una gran fiesta en el día previsto en que habría de despedirse del mundo a su manera. Entre escépticos y divertidos, sus amigos se apuntaron a la ocasión. Se abrieron botellas, se improvisaron discursos y entre fraternales abrazos se celebraron la amistad y la camaradería. 
Al acercarse en la noche el plazo estipulado, las especulaciones se disparan. Alguien asegura que Saúl esconde en su boca una cápsula de cianuro. Otros apuestan por el salto al vacío o por un profundo corte en las muñecas. Hay conjeturas acerca de una ingestión de tranquilizantes. Algún amago de desmayo se combina con susurros, ayer y secretos al oído. Todos los ojos se clavan en los movimientos de Saúl quien, medio borracho y feliz, olvida sus tratos con la muerte gracias a los ojazos y el redondísimo trasero de una morena.

Pasada la medianoche, profundamente decepcionados y con malas caras, los invitados dando un portazo se retiran.

\section{«Cadena alimenticia»}

Gustavo Laverde Sánchez Los gusanos decidieron contratar a las zorras como guardaespaldas; así, los pollos y las gallinas, por más osados que fueran, no se atreverían a tocarlos. Al cabo del tiempo, estas aves murieron de hambre, por falta de alimento, y las zorras se vieron obligadas a comer gusanos.

\section{«Visita de pésame»}

Adalberto Agudelo Duque A Manuel Salvador lo mataron los pájaros. En venganza por las tórtolas caídas, los colibríes y los gorriones asesinados merced a su ojo implacable con la cauchera de ocho líneas. Tal vez lo mataron por piedad, para que no sufriera en vida todas las muertes de los pichones huérfanos y los huevos abandonados en los nidos. Recuerdo que la noche del velorio, como a las once, tal vez más tarde, entró por la puerta un afrechero. Con saltos cortos y mirando rápido y nerviosamente a los circunstantes, voló al fin sobre el ataúd de tablas pegadas a clavo y martillo. Lo recorrió de arribabajo y de izquierdaderecha. Se detuvo un momento en el diminuto ventanal puesto ahí como una ojiva o un espejo para mirar al otro lado del infinito. Reconoció los rasgos, el ojo negro, grande, profundo, por donde entró la agonía. Agitó las alas y silbó su canción de todas las mañanas. Después trepó a la solera y se perdió en el agujero más grande de la noche por el agujero más pequeño de la casa. 